\title{
VOLUMNI UDIO VIŠEREDNIH DRVNIH TRAKOVA U STRUKTURI DEBLA I GRANA OBIČNE BUKVE (Fagus silvatica L.)
}

\section{The volume ratio of the multiple row wood stripes in the structure of trunk and the branches of common beech ( Fagus silvatica $L$.)}

\author{
Safet Gurda ${ }^{l}$, Muhamed Bajric ${ }^{1}$
}

\begin{abstract}
The paper presents the results of the studies on:

- the variations of the volume ratio of multiple row stripes within trunk of beech(Fagus silvatica $L$.) and

- variations of the volume ratio of multiple row stripes within normal and tension tree branches.
\end{abstract}

Key words: beech, multiple layer wood stripe, normal tree, tension tree.

\section{Izvod}

U ovom radu prezentirani su rezultati istraživanja o:

- varijacijama volumnog udjela višerednih drvnih trakova unutar debla bukve i

- varijacijama volumnog udjela višerednih drvnih trakova unutar normalnog i tenzijskog drveta grana.

Ključne riječi : bukva, višeredni drvni trak, normalno drvo, tenzijsko drvo.

\section{Uvod - Introduction}

Radijalni parenhim bukovine izgrađuje homocelularne, jedno do višeredne drvne trakove. Široki traci zauzimaju oko $1 / 10$ površine poprečnog presjeka. Aksijalni parenhim bukovine je malobrojan, apotrhealno difuzan, paratrahealno oskudan ili graničan. Njegov udio u građi drveta domaće bukovine je zanemarljiv.

Drvni traci bitno utiču na tehnička svojstva drveta. Direktno djeluju na koheziju drveta, a time i na osobine uzrokovane kohezijom (PETRIĆ I ŠćUKANEC, 1986).

\footnotetext{
${ }^{1}$ Šumarski fakultet Univerziteta u Sarajevu - Faculty of Forestry University of Sarajevo
} 


\section{Materijal i metod rada-Materials and Methods}

Materijal za ovo istraživanje potiče iz 59 odjela GJ «Kalin Radovan», ŠPP "Koprivnica", Bugojno. Izabrano je pet dominantnih zdravih, pravnih i približno jednakih stabala prečnika na prsnoj visini $40-50 \mathrm{~cm}$. Nakon obaranja, na svakom stablu je odabrano po 6 grana prečnika $5-7 \mathrm{~cm}$ (donje, srednje i gornje). Iz svih grana rezani su kolutovi na svakih $0,5 \mathrm{~m}$ (na 0,$5 ; 1,0$ itd.) do udaljenosti gdje su se mogle izrezati kockice za rezanje poprečnih i tangentnih presjeka. Na svim deblima na 4,0 m od panja izrezani su kolutovi visine $10 \mathrm{~cm}$.

Iz uzetih kolutova u određenim godovima vađene su probe za macerate $\mathrm{i}$ histološke preparate. Izrada preparata izvršena je na uobičajeni način.

Mjerenje volumnog udjela višerednih drvnih trakova izvršeno je na histološkim preparatima mikroskopom Reichert uz pomoć Leitzovog integracionog stolića 12,5 x 4,5 (GURDA, 1990).

\section{Rezultati rada - Results of work}

\subsection{Volumni udio višerednih drvnih trakova u građi debla The volume ratio of the multiple row tree stripes in the trunk structure}

Kumulativni podaci volumnog udjela višerednih trakova u građi debla dobiveni su na osnovu 430 mjerenja i prikazani su na grafikonu 1.

Volumni udio višerednih trakova varira u granicama od 8,25 do $29,26 \%$, s prosjekom $12,75 \pm 0,235 \%$ i standardnom devijacijom $2,49 \pm 0,166 \%$.

Odnos između volumnog udjela višerednih trakova i starosti goda može se prikazati sljedećim analitičkim izrazom:

$y=10,3890+0,06713 x-0,0002409 x^{2}$, sa indeksom korelacije $R=0,977$

gdje je :

y - volumni udio višerednih trakova, a

$\mathrm{x}$ - starost goda.

Dobiveni indeks korelacije kazuje da je prema gornjoj jednačini volumni udio višerednih trakova u deblu skoro u potpunoj korelaciji sa starosti goda.

\subsection{Volumni udio višerednih drvnih trakova u normalnom drvetu grana The volume ratio in the multiple row wood stripes in normal tree branches}

Volumni udio višerednih drvnih trakova u normalnom drvetu grana dobiven je na temelju 2120 mjerenja i prikazan je na grafikonu 1. 


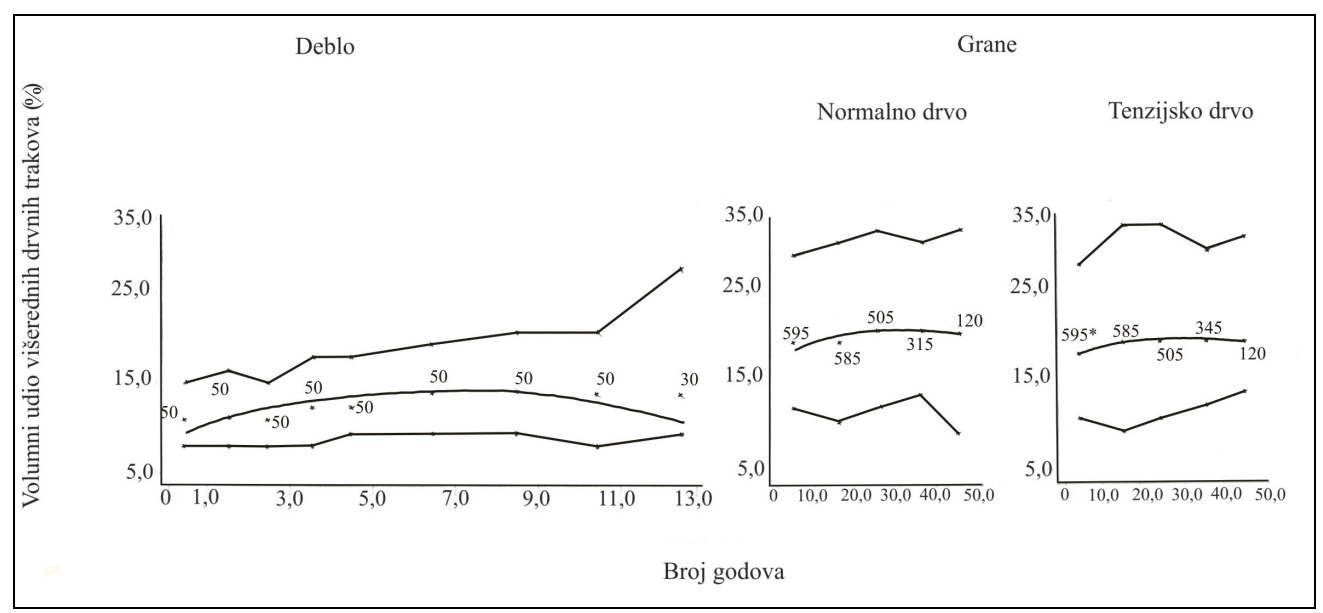

Grafikon 1. Volumni udio višerednih drvnih trakova

Graf. 1. The volume ratio of the multiple row wood stripes

Variranje je u granicama od 10,45 do $33,11 \%$, s prosjekom $20,76 \pm 0,1886 \%$ i standardnom devijacijom $4,43 \pm 0,1338 \%$.

Odnos između volumnog udjela višerednih drvnih trakova i starosti goda može se prikazati sljedećim analitičkim izrazom:

$$
\mathrm{y}=18,8190+0,1691 \mathrm{x}-0,002693 \mathrm{x}^{2}, \text { sa indeksom korelacije } \mathrm{R}=0,978 ;
$$

gdje je:

y - volumni udio višerednih trakova, a

$\mathrm{x}$ - starost goda.

Dobiveni indeks korelacije kazuje da je prema gornjoj jednačini zavisnost volumnog udjela višerednih trakova u građi normalnog drveta grana u skoro potpunoj korelaciji sa starosti goda.

\subsection{Volumni udio višerednih drvnih trakova na različitim položajima normalnog drveta grana u krošnji \\ The volume ration in the multiple row wood stripes at different positions of the normal branches in the tree crown}

Volumni udio višerednih drvnih trakova u normalnom drvetu donjih grana dobiven je na osnovu 920 mjerenja i prikazan je na grafikonu 2. 


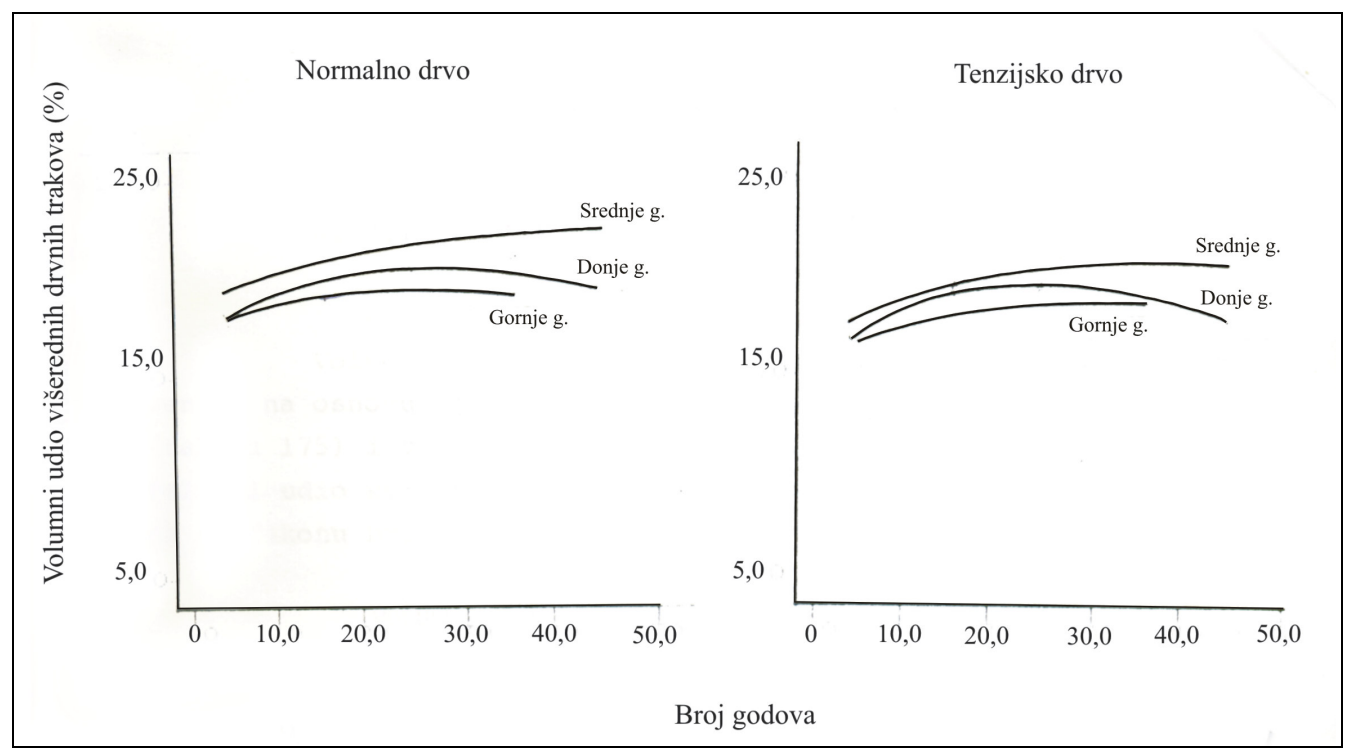

Grafikon 2. Zavisnost volumnog udjela višerednih drvnih trakova od starosti goda na različitim položajima grana u krošnji

Graf 2. Dependence of the volume ratio of the multiple row stripes from the alburnum age at differnet positions in the tree crown

Volumni udio višerednih trakova varira u granicama od 10,45 do $33,11 \%$, s prosjekom $20,36 \pm 0,320 \%$ i standardnom devijacijom 4,96 $\pm 0,227 \%$.

Kumulativni rezultati mjerenja volumnog udjela višerednih trakova u normalnom drvetu srednjih grana dobiveni su na osnovu 770 mjerenja i prikazani su na grafikonu 2.

Volumni udio višerednih trakova varira u granicama od 13,26 do 32,19\%, s prosjekom $21,82 \pm 0,297 \%$ i standardnom devijacijom $4,21 \pm 0,210 \%$.

U normalnom drvetu gornjih grana volumni udio višerednih trakova dobiven je na osnovu 430 mjerenja i prikazan je na grafikon 2.

Volumni udio višerednih trakova varira u granicama od 13,21 do $28,17 \%$, s prosjekom $19,85 \pm 0,298 \%$ i standardnom devijacijom $3,16 \pm 0,211 \%$.

Odnos između volumnog udjela višerednih trakova i starosti goda može se prikazati sljedećim analitičkim izrazima:

a) za donje grane

$$
\mathrm{y}=17,8400+0,2223 \mathrm{x}-0,003693 \mathrm{x}^{2}, \text { sa indeksom korelacije } \mathrm{R}=0,979 ;
$$

b) za srednje grane

$$
y=20,5301+0,06737 x-0,0003714 x^{2}, \text { sa indeksom korelacije } R=0,680 ;
$$


c) za gornje grane

$$
y=18,5349+0,1061 x-0,001475 x^{2}, \text { sa indeksom korelacije } R=0,865 ;
$$

gdje je:

$\mathrm{y}$ - volumni udio višerednih trakova, a

$\mathrm{x}$ - starost goda.

Dobiveni indeksi korelacije pokazuju da je prema gornjim jednačinama zavisnost volumnog udjela višerednih trakova u srednjim i gornjim granama u jakoj korelaciji, a u donjim skoro u potpunoj korelaciji sa starosti goda.

\subsection{Volumni udio višerednih drvnih trakova na različitim udaljenostima presjeka normalnog drveta grana \\ The volume ratio of the multiple row wood stripes at different distances of the cross section of normal tree branches}

Kumulativni rezultati mjerenja volumnog udjela višerednih trakova $u$ normalnom drvetu grana na udaljenosti 0,$5 ; 1,0 ; 1,5 ; 2,0$ i $2,5 \mathrm{~m}$ od debla prikazani su na grafikonu 3.

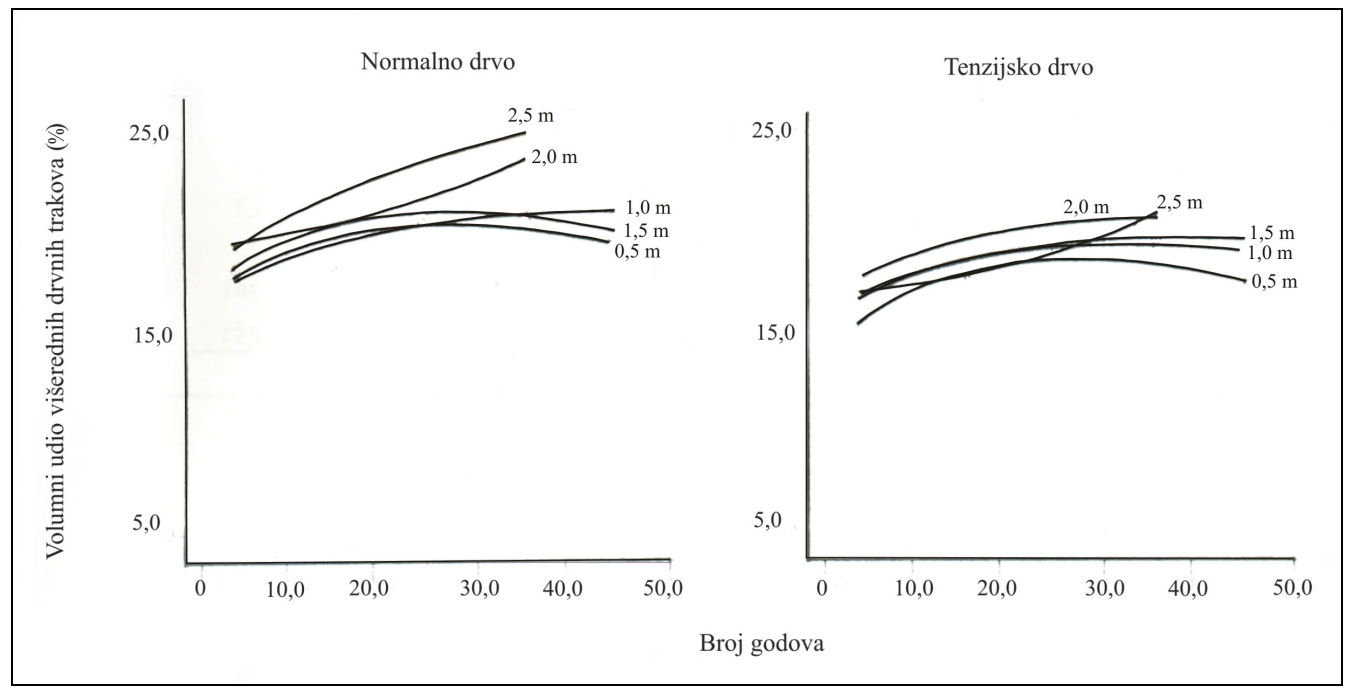

Grafikon 3. Zavisnost volumnog udjela višerednih drvnih trakova od starosti goda na različitim udaljenostima presjeka grana

Graf 3. Dependence of the volume ratio of the multiple row stripes from the age alburnum at different distances from the branches cross sections

$\mathrm{Na}$ osnovu 580 mjerenja dobiven je volumni udio višerednih trakova na udaljenosti $0,5 \mathrm{~m}$ od debla.Variranje je u granicama od 11,44 do $29,11 \%$, s prosjekom $19,18 \pm 0,303 \%$ i standardnom devijacijom $3,72 \pm 0,214 \%$. 
Volumni udio višerednih trakova na udaljenosti $1,0 \mathrm{~m}$ od debla dobiven na osnovu 555 mjerenja varira u granicama od 10,45 do 30,26\%, s prosjekom 20,26 \pm $0,322 \%$ i standardnom devijacijom $3,87 \pm 0,228 \%$.

$\mathrm{Na}$ udaljenosti $1,5 \mathrm{~m}$ od debla u normalnom drvetu grana izvršeno je 495 mjerenja volumnog udjela višerednih trakova. Volumni udio višerednih trakova varira u granicama od 13,70 do $33,11 \%$, s prosjekom $20,74 \pm 0,379 \%$ i standardnom devijacijom 4,30 $\pm 0,268 \%$.

Granice u kojima se kreće volumni udio višerednih trakova na udaljenosti 2,0 m od debla su od 14,44 do 30,26\%, s prosjekom $21,97 \pm 0,472$ i standardnom devijacijom 4,03 \pm $0,195 \%$, a kumulativni rezultati su dobiveni na osnovu 280 mjerenja.

Variranje volumnog udjela višerednih trakova na udaljenosti $2,5 \mathrm{~m}$ od debla je u granicama od 15,26 do $32,19 \%$, s prosjekom $23,64 \pm 0,648 \%$ i standardnom devijacijom 4,79 $\pm 0,458 \%$, na temelju 210 mjerenja.

Odnos između volumnog udjela višerednih trakova i starosti goda može se prikazati sljedećim analitičkim izrazima:

a) za $0,5 \mathrm{~m}$ od debla: $\mathrm{y}=16,6537+0,2791 \mathrm{x}-0,004564 \mathrm{x}^{2}$, sa indeksom korelacije $\mathrm{R}=0,916$;

b) za $1.0 \mathrm{~m}$ od debla: $\mathrm{y}=18,888+0,07757 \mathrm{x}-0,0002714 \mathrm{x}^{2}$, sa indeksom korelacije $\mathrm{R}=0,902$;

c) za $1.5 \mathrm{~m}$ od debla: $\mathrm{y}=16,7348+0,2896 \mathrm{x}-0,004028 \mathrm{x}^{2}$, sa indeksom korelacije $\mathrm{R}=0,889$;

d) za $2.0 \mathrm{~m}$ od debla: $\mathrm{y}=18,8600+0,1280 \mathrm{x}+0,001200 \mathrm{x}^{2}$, sa indeksom korelacije $\mathrm{R}=0,992$;

c) za $2.5 \mathrm{~m}$ od debla: $\mathrm{y}=19,3457+0,2674 \mathrm{x}-0,002950 \mathrm{x}^{2}$, sa indeksom korelacije $\mathrm{R}=0,999$;

gdje je:

$\mathrm{y}$ - volumni udio višerednih trakova, a

$\mathrm{x}$ - starost goda.

Dobiveni indeksi korelacije u navedenim jednačinama kazuju da je u normalnom drvetu grana na udaljenosti 0,$5 ; 1,0 ; 2,0$ i 2,5 od debla zavisnost volumnog udjela višerednih trakova skoro u potpunoj korelaciji sa starosti goda, a na udaljenosti $1,5 \mathrm{~m}$ u jakoj korelaciji.

\subsection{Volumni udio višerednih drvnih trakova u tenzijskom drvetu grana The volume ratio of the multiple}

Kumulativni podaci mjerenja volumnog udjela višerednih trakova u tenzijskom drvetu grana dobiveni su na osnovu 2120 mjerenja i prikazani su na grafikonu 1. 
Volumni udio višerednih trakova varira u granicama od 10,48 do $32,18 \%$, s prosjekom 19,35 $\pm 0,183 \%$ i standardnom devijacijom 4,30 $\pm 0,129 \%$.

Odnos između volumnog udjela višerednih trakova i starosti goda može se prikazati sljedećim analitičkim izrazom: gdje je :$$
\mathrm{y}=17,0781+0,1901 \mathrm{x}-0,002864 \mathrm{x}^{2} \text {, sa indeksom korelacije } \mathrm{R}=0,991 \text {; }
$$

y - volumni udio višerednih trakova, a

$\mathrm{x}$ - starost goda.

Dobiveni indeks korelacije kazuje da je prema gornjoj jednačini zavisnost volumnog udjela višerednih trakova u skoro potpunoj korelaciji sa starosti goda.

\subsection{Volumni udio višerednih drvnih trakova na različitim položajima tenzijskog drveta grana u krošnji \\ The volume ratio of the multiple row wood stripes at various positions of the tension tree branches in the tree crown}

Volumni udio višerednih trakova u tenzijskom drvetu donjih grana dobiven je na osnovu 920 mjerenja i prikazan je na grafikonu 2. Variranje je u granicama od 10,48 do $32,18 \%$, s prosjekom 19,30 $\pm 0,307 \%$ i standardnom devijacijom 4,75 $\pm 0,217 \%$. Kumulativni rezultati mjerenja volumnog udjela višerednih trakova u tenzijskom drvetu srednjih grana dobiveni su na osnovu 770 mjerenja i prikazani su na grafikonu 2.Volumni udio višerednih trakova varira u granicama od 13,28 do $29,15 \%$, s prosjekom 19,86 $\pm 0,292 \%$ i standardnom devijacijom 4,13 $\pm 0,206 \%$.

$\mathrm{U}$ tenzijskom drvetu gornjih grana volumni udio višerednih trakova dobiven je na osnovu 430 mjerenja i prikazan je na grafikonu 2. Volumni udio višerednih trakova kreće se u granicama od 12,91 do 27,91\%, s prosjekom 18,61 $\pm 0,329 \%$ i standardnom devijacijom 3,48 $\pm 0,232 \%$.

Odnos između volumnog udjela višerednih trakova i starosti goda može se prikazati sljedećim analitičkim izrazima :

a) za donje grane

$$
y=16,5374+0,2496 x-0,00422 x^{2} \text {, sa indeksom korelacije } R=0,999 ;
$$

b) za srednje grane

$$
\mathrm{y}=17,8037+0,1307 \mathrm{x}-0,0009643 \mathrm{x}^{2}, \text { sa indeksom korelacije } \mathrm{R}=0,945
$$

c) za gornje grane

$$
y=17,2003+0,1147 x-0,001575 x^{2}, \text { sa indeksom korelacije } R=0,986
$$

gdje je:

$\mathrm{y}$ - volumni udio višerednih trakova, a

$\mathrm{x}$ - starost goda. 
Dobiveni indeksi korelacije kazuju da je volumni udio višerednih trakova u tenzijskom drvetu donjih, srednjih i gornjih grana u skoro potpunoj korelaciji sa starosti goda.

\subsection{Volumni udio višerednih drvnih trakova na različitim udaljenostima presjeka tenzijskog drveta grana \\ The volume ratio of the multiple row wood stripes at different distances from the cross section of the tension tree branches}

Kumulativni rezultati mjerenja volumnog udjela višerednih trakova u tenzijskom drvetu grana na udaljenostima 0,$5 ; 1,0 ; 1,5 ; 2,0$ i $2,5 \mathrm{~m}$ od debla prikazani su na grafikonu 3.

Volumni udio višerednih trakova na udaljenosti $0,5 \mathrm{~m}$ od debla dobiven na osnovu 580 mjerenja varira u granicama od 10,48 do 31,19\%, s prosjekom 18,09 \pm $0,354 \%$ i standardnom devijacijom $4,35 \pm 0,250 \%$.

$\mathrm{Na}$ osnovu 555 mjerenja dobiven je volumni udio višerednih trakova na udaljenosti $1,0 \mathrm{~m}$ od debla. Variranje je u granicama od 12,68 do $26,29 \%$, s prosjekom $18,74 \pm 0,254 \%$ i standardnom devijacijom 3,05 $\pm 0,179 \%$.

$\mathrm{Na}$ udaljenosti $1,5 \mathrm{~m}$ od debla izvršeno je 495 mjerenja volumnog udjela višerednih trakova. Volumni udio višerednih trakova varira u granicama od 13,21 do $30,48 \%$, s prosjekom 19,45 $\pm 0,368 \%$ i standardnom devijacijom 4,18 $\pm 0,260 \%$.

Variranje volumnog udjela višerednih trakova na udaljenosti $2,0 \mathrm{~m}$ od debla je od 12,40 do $30,41 \%$, s prosjekom $20,55 \pm 0,497 \%$ i standardnom devijacijom 4,24 $\pm 0,351 \%$. Rezultati su dobiveni na osnovu 280 mjerenja.

Granice u kojima se kreće volumni udio višerednih trakova na udaljenosti 2,5 m od debla su od 15,40 do 32,18\%. Izvršeno je 210 mjerenja.Prosjek je 19,63 \pm $0,625 \%$ sa standardnom devijacijom 4,62 $\pm 0,442 \%$.

Odnos između volumnog udjela višerednih trakova i starosti goda može se prikazati sljedećim analitičkim izrazima:

a) za 0,5 m od debla: $y=14,3826+0,3841 x-0,006886 x^{2}$, sa indeksom korelacije $\mathrm{R}=0,984$

b) za $1,0 \mathrm{~m}$ od debla $: \mathrm{y}=15,6967+0,2593 \mathrm{x}-0,003764 \mathrm{x}^{2}$, sa indeksom korelacije $\mathrm{R}=0,990$;

c ) za $1,5 \mathrm{~m}$ od debla : $\mathrm{y}=16,1796+0,3062 \mathrm{x}-0,005071 \mathrm{x}^{2}$, sa indeksom korelacije $\mathrm{R}=0,966$;

d) za 2,0 m od debla: $y=17,5975+0,1810 x-0,001500 \mathrm{x}^{2}$, sa indeksom korelacije $\mathrm{R}=0,973$;

e) za 2,5 m od debla: $\mathrm{y}=16,8992+0,1076 \mathrm{x}-0,000950 \mathrm{x}^{2}$, sa indeksom korelacije $\mathrm{R}=0,989$; 
gdje je:

y - volumni udio višerednih trakova, a

$\mathrm{x}$ - starost goda.

Dobiveni indeksi korelacije kazuju da je prema navedenim jednačinama zavisnost volumnog udjela višerednih trakova u tenzijskom drvetu grana na udaljenosti 0,$5 ; 1,0 ; 1,5 ; 2,0$ i $2,5 \mathrm{~m}$ od debla u skoro potpunoj korelaciji sa starosti goda.

\section{Zaključak - Conclusion}

Na osnovu dobivenih rezultata može se zaključiti sljedeće:

1. Volumni udio višerednih trakova u deblu kreće se u granicama od 8,25 do $29,26 \%$, s prosjekom $12,75 \pm 0,235 \%$ i standardnom devijacijom $2,49 \pm 0,166 \%$, a u skoro potpunoj je korelaciji sa starosti goda ( $\mathrm{R}=0,977$ ).

2. Volumni udio višerednih trakova $\mathrm{u}$ normalnom drvetu grana varira $\mathrm{u}$ granicama od 10,45 do $33,11 \%$, s prosjekom $20,76 \pm 0,1886 \%$ i standardnom devijacijom 4,43 $\pm 0,1338 \%$, a u skoro potpunoj je korelaciji sa starosti goda ( $\mathrm{R}=0,978$ ).

Volumni udio višerednih trakova u normalnom drvetu grana raste od donjih do srednjih grana, a dalje prema vrhu krošnje opada.

Volumni udio višerednih trakova u normalnom drvetu grana postepeno raste od $0,5 \mathrm{~m}$ do vrha grana.

3. Volumni udio višerednih trakova u tenzijskom drvetu grana varira u granicama od 10,48 do 32,18 \%, s prosjekom 19,35 $\pm 0,183 \%$ i standardnom devijacijom $4,30 \pm 0,129 \%$, a u skoro potpunoj je korelaciji sa starosti goda $(\mathrm{R}=0,991)$.

Volumni udio višerednih trakova u tenzijskom drvetu grana postepeno raste od donjih do srednjih grana, a zatim prema vrhu krošnje opada.

Volumni udio višerednih trakova postepeno raste od $0,5-2,0 \mathrm{~m}$ od debla, a dalje prema vrhu grana opada.

4. Volumni udio višerednih drvnih trakova u normalnom drvetu grana veći je za $8,01 \%$ od volumnog udjela u deblu, a za 1,41\% od volumnog udjela u tenzijskom drvetu grana.

\section{Literatura - References}

1. CHALK, L. (1970): Short fibres with clearly defined intrusive growth, with special reference to Fraxinus, Suplement 1 to the Botanical J. of the Linnulan Society, Vol.63, AP.

2. ERAK, S.(1968): Prilog poznavanju veličine i gustoće nekih elemenata anatomske građe bukve (Fagus moesiaca Dom.) iz srednje Bosne, »Pregled» br.2, Sarajevo.

3. ERAK, S. (1967): Anatomska građa drva medvjeđe lijeske (Corylus colurna L.), magistarski rad, Sarajevo. 
4. GuRDA, S. (1990): Strukturne karakteristike drveta grana obične bukve (Fagus silvatica $L$.) iz područja Bosne, Disertacija, Zagreb.

5. PetRić, B., ŠćUKANEC, V. (1980): Neke strukturne karakteristike domaće bukovine (Fagus silvatica L.), Drvna industrija, br. 9-10, Zagreb.

6. Petrić, B., ŠćUKANEC, V. (1986): Struktura drva domaće bukve (Fagus silvatica L.). Kolokvij o bukvi, Velika, 22 - 24.11.1984,Šumarski fakultet Zagreb.

\section{Summary - Sažetak}

The paper presents the results of the studies of variation of the volume ratio in the multiple row wood stripes within the bees tree trunk (Fagus silvatica L.), and in the normal and tension tree branches.

The volume ratio of the multiple row wood stripes in the trunk varies between 8,25 and $29,26 \%$ (with an average value of $12,75 \pm 0,235 \%$ and standard deviation of $2,49 \pm 0,166 \%)$.

The variation of the volume ratio in the multiple row stripes in normal tree branches was between 10,45 and $33,11 \%$ (with an average value of $20,76 \pm 0,1886 \%$ and standard deviation of $4,43 \pm 0,1338 \%$ ).

In the tension tree branches the volume ratio of the multiple row stripes was within the limits of 10,48 up to $32,18 \%$ (with an average value of $19,35 \pm 0,183 \%$ and standard deviation of $4,30 \pm 0,129 \%)$.

The volume ratio in the multiple row stripes in normal tree branches was higher for $8,01 \%$ from the volume ratio in the trunk, and for $1,41 \%$ from the volume ratio in the tension tree branches. 